\title{
PEDIATRIC ORIGINAL ARTICLE Impaired fasting glucose prevalence in two nationwide cohorts of obese children and adolescents
}

\author{
E Hagman ${ }^{1,5}$, T Reinehr $^{2,5}$, J Kowalski ${ }^{1}$, A Ekbom $^{3}$, C Marcus $^{1,6}$ and RW Holl ${ }^{4,6}$
}

OBJECTIVE: Impaired fasting glucose (IFG), a pre-stage to type 2 diabetes in adults, is also present in obese children. A large variation of the occurrence has been recorded, but the true prevalence is unknown due to lack of larger representative cohort studies. This study was implemented to investigate the prevalence of IFG in two nationwide cohorts of obese children and to find factors that affect the risk of IFG.

DESIGN: A cross-sectional study based on data collected from two nationwide registers of obese children in Germany and Sweden, respectively.

SUBJECTS: Subjects included were 2-18 years old. 32907 subjects with fasting glucose were eligible in Germany and 2726 in Sweden. Two cutoff limits for IFG were used: $5.6-6.9 \mathrm{mmolI}^{-1}$ according to the American Diabetes Association (ADA) and 6.1-6.9 $\mathrm{mmolI}^{-1}$ according to the World Health Organization (WHO). Variables collected were gender, age and degree of obesity. Logistic regression was used to calculate odds ratios.

RESULTS: The total prevalence of IFG among obese children in the German cohort according to the ADA was $5.7 \%$ and according to the WHO it was $1.1 \%$. In Sweden, the corresponding prevalence was $17.1 \%$ and $3.9 \%$, respectively. IFG risk was correlated with increasing age, male sex and degree of obesity.

CONCLUSIONS: IFG is highly prevalent among obese children. Age and degree of obesity are positively correlated with the risk of having IFG. There are large regional differences. After adjustments, obese children in Sweden, due to unknown reasons, have a 3.4- to 3.7-fold higher risk of having IFG than obese children in Germany.

International Journal of Obesity (2014) 38, 40-45; doi:10.1038/ijo.2013.124

Keywords: impaired fasting glycemia; pre-diabetes; childhood obesity

\section{INTRODUCTION}

Obesity in childhood and adolescence has become a massive health problem in many countries, including both developed and less-developed countries. High body mass index (BMI) in childhood is associated with an increased risk of cardiovascular heart disease events in adulthood. ${ }^{1}$ Severe obesity in young adulthood results in 13-years loss of expected life. ${ }^{2}$ An early metabolic consequence of obesity is disturbed glucose and insulin homeostasis. ${ }^{3}$ One of these consequences is impaired fasting glucose (IFG), which was introduced in the late 1990 s by the American Diabetes Association (ADA) and World Health Organization (WHO) as a pre-diabetic stage referring to the fasting levels of plasma glucose concentration above the upper normal range, but below those that are diagnostic for diabetes. The glucose range for IFG differs between organizations: the ADA glucose range is $5.6-6.9 \mathrm{mmoll}^{-1}$, whereas WHO has stricter criteria, $6.1-6.9 \mathrm{mmoll}^{-1}$. 4,5 Both criteria are used and there is no consensus on IFG, especially not in children and adolescents.

In adult individuals, IFG is a predictor of type 2 diabetes. ${ }^{6-8}$ Further, in adults IFG is associated with fatal and non-fatal cardiovascular disease, ${ }^{9}$ increased risk for cancers ${ }^{10}$ and all-cause mortality. ${ }^{11}$ IFG in obese children is associated with increased intima-media thickness, ${ }^{12}$ a predictive factor for atherosclerosis. The mechanism behind IFG is still not fully understood, but IFG seems to be a result of impaired insulin secretion, indicating beta-cell dysfunction and also increased hepatic glucose output. $^{13}$

A large variation of IFG prevalence has been reported in obese adolescents. European studies are reporting prevalences from $0 \%$ in Italy ${ }^{14}$ (WHO criteria) to $16 \%$ in the Netherlands (ADA criteria), ${ }^{15,16}$ and American studies range between 2 and $9 \%$ (WHO criteria) and $15-47 \%$ (ADA criteria). ${ }^{17-19}$ However, most reports have been based on samples too small to be representative for entire populations, and it is, therefore, unclear whether the marked variations in prevalence represent a true variation among obese children in different geographic areas. $^{14,19,20}$ In addition, IFG in younger children is rarely studied. Consequently, this study was implemented to estimate the prevalence of the pre-diabetic state IFG and factors influencing the risk for IFG among both children and adolescents suffering from obesity in Germany and Sweden, using nationwide register data in the two countries.

${ }^{1}$ Division of Pediatrics, Department of Clinical Science, Intervention and Technology, Karolinska Institutet, Stockholm, Sweden; ${ }^{2}$ Department of Pediatric Endocrinology, Diabetes, and Nutrition Medicine, University of Witten/Herdecke, Datteln, Germany; ${ }^{3}$ Clinical Epidemiology Unit, Department of Medicine, Karolinska Institutet, Stockholm, Sweden and ${ }^{4}$ Institute of Epidemiology and Medical Biometry University of Ulm, Ulm, Germany. Correspondence: Professor C Marcus, Division of Pediatrics, Department of Clinical Science, Intervention and Technology, Karolinska Institutet, S-141 86 Stockholm, Sweden.

E-mail: claude.marcus@ki.se

${ }^{5}$ Shared first authorship.

${ }^{6}$ Shared last authorship.

Received 30 October 2012; revised 18 June 2013; accepted 23 June 2013; accepted article preview online 5 July 2013 ; advance online publication, 30 July 2013 


\section{SUBJECTS AND METHODS}

\section{Subjects}

This study is based on two cohorts: one from Germany and one from Sweden. All data were achieved prospectively. Both cohorts represent subjects from both urban and rural areas, and in both countries everybody, independently of socioeconomic status, can apply for healthcare.

On the basis of the German guidelines for diagnosis and treatment of overweight children and adolescents (www.a-g-a.de), a standardized computer software package using the visual FoxPro 9.0 compiler was developed for standardized multicenter prospective documentation of overweight children and adolescents (APV) in 1999.. ${ }^{21}$ Participation in this quality control program is the precondition for certification of pediatric obesity treatment centers by the German Obesity Society (DAG) and for funding of the treatment by health insurances allowing integration of the great majority of German Obesity treatment centers for children and adolescents. Anthropometric parameters, metabolic control and treatment modalities (multiprofessional composition and intensity of lifestyle interventions) are documented longitudinally by the software. The software allows standardized patient reports, local aggregation of data and patient selection according to the multiple criteria. Anonymized data are transmitted for central analysis. Inconsistent data are reported back to the centers twice a year for correction. Owing to non-industrial grants, this quality assessment is free of charge. This system allows establishing a large data collection; more than $90 \%$ of all centers specialized in pediatric obesity care in Germany participated in this study $(n=178)$ between January 2001 and December 2009.

The Swedish material is from a nationwide childhood obesity treatment registry (BORIS-registry, www.e-boris.se) where 20 of 24 (83.3\%) pediatric clinics that treat obesity are enrolled. The BORIS-registry is recommended for use by The National Board of Health and Welfare, and The Swedish Association of Local Authorities and Regions. Data have been collected from all over the country between the years of 1995 and 2010. Patients included in the registry are children and adolescents up to 25 years of age undergoing treatment for their overweight or obesity. The quality of the registry is secured by frequent randomized sampling of the collected data.

Inclusion criteria for this study were children and adolescents between 2 and 18 years of age, obese according to the International Obesity Taskforce (IOTF) criteria ${ }^{22}$ with an eligible fasting glucose measurement. Only the first measurement of fasting glucose, which, generally, is at the beginning of the treatment, was used to reduce the possible effect of treatment on IFG prevalence. Exclusion criteria for both data sets were diabetes (diagnosed with oral glucose tolerance test or fasting plasma glucose $\geqslant 7.0 \mathrm{mmolI}^{-1}$ ), syndromal obesity (Laurence-Moon-Bardet-Biedl syndrome and PraderWilli syndrome), secondary obesity (central nervous system damage, leptin deficiency, myelomeningocele, mutation in the MC4-receptor, leptinreceptor, POMC and hypothalamic disturbances), and patients with Down Syndrome, endocrine disorders (except for well-controlled hypothyroidism), and patients who at the time of blood sampling were on drugs that could affect the glucose homeostasis, including metformin.

At the time of the extraction of data for this study, 65688 (46\% boys and $54 \%$ girls) patients in the German cohort and 5305 (51.9\% boys and $48.1 \%$ girls) patients in the Swedish cohort were available. A total of 32907 (47.7\% boys and $52.3 \%$ girls) German and 2726 (52.4\% boys and $47.6 \%$ girls) Swedish patients fulfilled the inclusion criteria. The number of subjects by reason for exclusion is summarized in Figure 1. No differences in age or degree of obesity between groups with and without fasting glucose measurement could be seen in the Swedish material. In the German cohort those with glucose measurements were slightly older and more obese. However, the minor differences in this large cohort are probably not of clinical relevance (Supplementary Table 1). In the German cohort, $\sim 0.04 \%$ of the German population were included, and in the Swedish cohort, $0.03 \%$ of the Swedish population were included. The prevalence of childhood obesity is approximately the same in Sweden and Germany. ${ }^{23}$ Thus, the same proportion of obese subjects is recruited for both registers.

\section{Definitions, measures and methods used}

We investigated the prevalence of IFG using both definitions from the ADA and $\mathrm{WHO}^{4,5}$ All children have undergone anthropometric measurements by staff at pediatric clinics. BMI was calculated as the weight in kilograms divided by the height in meter squared $\left(\mathrm{kg} / \mathrm{m}^{2}\right)$. The international age- and gender-specific BMI cutoff points defined by the IOTF were used to define childhood obesity. As BMI is age and gender dependent, BMI standard deviation scores (BMI SDS), adjusted for age and gender, were used to

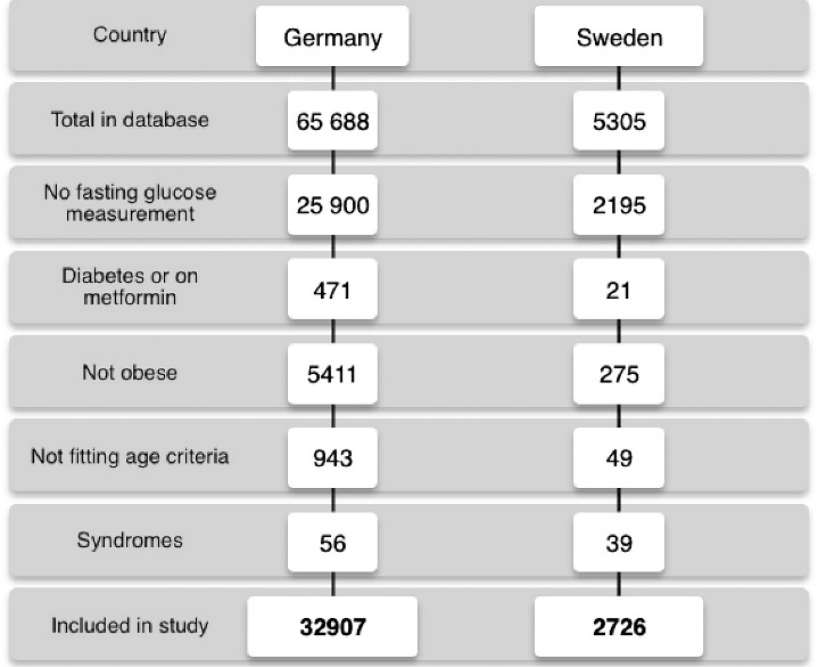

Figure 1. The exclusion process for the German and the Swedish databases.

compare the degree of obesity within the populations studied. Two different models of BMI SDS were used, based on German and Swedish populations, respectively. ${ }^{24,25}$ The German model is denoted as BMI SDS (Ger) and the Swedish model as BMI SDS (Swe). Blood samples were obtained after an overnight fast for the measurement of plasma glucose. Earlier, whole blood-glucose measurements in the Swedish material (18.9\%) were adjusted to be comparable to plasma glucose in accordance with international standards. ${ }^{26}$ This was not needed for the German blood samples, as all measurements were calibrated as plasma glucose.

The methodology to analyze fasting glucose in Germany is regulated by 'RILIBÄK' and in Sweden by 'EQUALIS'. Both of these policy frameworks recommend venous plasma glucose.

Variables used in this study were gender, age and the German and Swedish models of BMI SDS. Age was divided into the following categories: $2-9,10-12.9,13-15.9$ and $16-18$ years. The degree of obesity was arbitrarily divided into six groups for both BMI SDS models. The number of patients in each group is shown in Table 1. To perform country-to-country specific adjustment, the following variables were used: age, degree of obesity and gender. Data from the two cohorts were pooled $(n=35633)$. In addition, there were also registry-specific variables. Both Germany and Sweden are divided into regions, Germany into the following: north or south, and west (old) or east (new) parts of Germany. Sweden was divided into six regions corresponding to county regions. Germany also has data on migration background defined as one or both parents being born outside of Germany, and data on socioeconomic risk (unemployed parents, broken home and low education).

To study a possible effect of treatment center on quality of glucose measurement, university institutions in Germany and Sweden were compared with pediatric clinics.

Ethical permission for data collection within the BORIS-cohort is obtained. The Regional Committee of Ethics, Stockholm, approves studies within the BORIS-cohort. For studies within the APV, the ethics committee of University of Ulm approved central analysis. Each German participating center complies with its local ethical and data management guidelines.

\section{Statistical analysis}

Data were processed and analyzed using the statistical programs SAS, version 9.3, and STATISTICA, version 10.0 (Stat Soft, Inc., Tulsa, OK, USA).

Data were presented using mean and standard deviation (s.d.). Linear regression was used for univariate analysis. Logistic regression was used to discriminate IFG from non-IFG in multivariable modeling, including the following variables for a country-specific analysis: gender, age categories and the two measures of BMI SDS. In the analysis of German data, regional and immigration categorization were used. In the analysis of Swedish data, regional categorization was used. The results are reported as odds ratio (OR) with the corresponding $95 \%$ confidence intervals (Cl). 


\section{RESULTS}

The mean ages of the German and Swedish subjects included in this study were 12.5 (s.d. 2.9) and 11.4 (s.d. 3.4) years, respectively. The German register had a slightly larger proportion of girls than boys, whereas the opposite was found in the Swedish population. The Swedish population was slightly more obese. The characteristics of both populations are described in Table 2 .

The total prevalence of IFG among obese children in the German cohort according to the ADA criteria is $5.7 \%$, and according to the WHO criteria it is $1.1 \%$. In Sweden, the corresponding prevalence is $17.1 \%$ and $3.9 \%$, respectively. Thus, Sweden had a threefold higher prevalence of IFG according to the ADA criteria and a 3.5-fold higher prevalence according to the WHO criteria among obese children and adolescents, compared with Germany.

When data from both countries were pooled, boys had a higher risk for IFG $(A D A)$ than girls. With the German BMI SDS, the OR is 1.24 (1.14-1.35) and with the Swedish BMI SDS 1.13 (1.03-1.22). Age is also positively correlated with increased risk for IFG. The highest risk for $\mathrm{IFG}_{(\mathrm{WHO})}$ was shown to be in the age of $13-15.9$ years compared with children under 9 years of age OR $=1.93$ (1.372.72). The degree of obesity is also strongly correlated with the risk for IFG in all models. All results from pooled data analysis are

Table 1. Frequency of subjects by age and BMI SDS

\begin{tabular}{|lcc|}
\hline & Germany & Sweden \\
& $\mathrm{n}(\%)$ & $\mathrm{n}(\%)$ \\
\hline Age & & \\
$2-9$ & $4080(12.4)$ & $705(25.9)$ \\
$10-12.9$ & $13180(40.0)$ & $802(29.4)$ \\
$13-15.9$ & $12225(37.2)$ & $930(34.1)$ \\
$16-18$ & $3422(10.4)$ & $289(10.6)$ \\
& $100 \%$ & $100 \%$ \\
BMI SDS (Ger) & & \\
$1.8-<2$ & & $65(2.4)$ \\
$2-<2.5$ & $3702(11.2)$ & $970(35.6)$ \\
$2.5-<3.0$ & $12766(38.8)$ & $1025(37.6)$ \\
$3.0-<3.5$ & $10666(32.4)$ & $477(17.5)$ \\
$3.5-<4.0$ & $4301(13.1)$ & $151(5.5)$ \\
$>4.0$ & $1178(3.6)$ & $38(1.4)$ \\
& $294(0.9)$ & $100 \%$ \\
$B M I$ SDS (Swe) & $100 \%$ & $76(2.8)$ \\
$2.3-<2.5$ & & $779(28.6)$ \\
$2.5-<3.0$ & & $941(34.5)$ \\
$3.0-<3.5$ & $4710(14.3)$ & $584(21.4)$ \\
$3.5-<4.0$ & $11573(35.2)$ & $238(8.7)$ \\
$4.0-<4.5$ & $9894(30.1)$ & $108(4.0)$ \\
$>4.5$ & $4675(14.2)$ &
\end{tabular}

Table 2. Descriptive statistics, mean (s.d.) for patient characteristics

\begin{tabular}{|c|c|c|}
\hline & $\begin{array}{c}\text { Germany mean } \\
\text { (s.d.) }\end{array}$ & $\begin{array}{c}\text { Sweden mean } \\
\text { (s.d.) }\end{array}$ \\
\hline$n$ & 32907 & 2726 \\
\hline Girls/Boys (\%) & $52.3 / 47.7$ & $47.6 / 52.4$ \\
\hline Age (years) & $12.5(2.9)$ & $11.4(3.4)$ \\
\hline $\mathrm{BMI}\left(\mathrm{kg} \mathrm{m}^{-2}\right)$ & $30.8(5.4)$ & $30.4(3.4)$ \\
\hline BMI SDS (Ger) $\left(\mathrm{kg} \mathrm{m}^{-2}\right)$ & $2.6(0.5)$ & $2.7(0.5)$ \\
\hline BMI SDS (Swe) $\left(\mathrm{kg} \mathrm{m}^{-2}\right)$ & $3.1(0.6)$ & $3.3(0.6)$ \\
\hline Fasting glucose $\left(\mathrm{mmoll}^{-1}\right)$ & $4.6(0.6)$ & $5.0(0.5)$ \\
\hline
\end{tabular}

shown in Table 3. Obese children and adolescents in Sweden have a 3.4-fold higher risk for IFG $($ ADA $)$ compared with Germany. For the WHO classification, in Sweden the obese children have a 3.7-fold increased risk of developing IFG compared with obese children in Germany.

The distribution of fasting glucose in Sweden and Germany is demonstrated in Figure 2.

When the country cohorts are studied separately in multivariate analysis, boys had a statistically significant higher risk for IFG (ADA) than girls (Table 4). The risk for IFG increases significantly with age in the Swedish population according to all univariate (Table 5) and multivariate models. This is also significant in the German population according to the ADA classification. In all models, both univariate and multivariate, children aged 9-12.9 years have a higher risk for IFG compared with children under the age of 9. All odds ratios for IFG calculated in multivariate models for Germany and Sweden, respectively, are presented in Table 4.

In the German registry-specific multivariate models adjusted for gender, age, BMI SDS (Swe) or BMI SDS (Ger), immigration data and regional data, it is shown that the Eastern states have a statistically significant higher risk for IFG than the Western states. For BMI SDS (Ger) the OR for $\mathrm{IFG}_{(\mathrm{WHO})}$ is 1.56 (1.18-2.05). In the German cohort, there was no statistically significant difference in the risk for IFG between ethnic Germans and immigrants. Neither did socioeconomic risk affect the risk for IFG. These results are independent of BMI SDS model or definition of IFG used.

In the registry-specific models for Sweden adjusted for gender, age, BMI SDS (Swe) and regional data, it is shown that when dividing Sweden into six regions the risk for $\mathrm{IFG}_{(\mathrm{ADA})}$ was statistically increased in the western part compared with most other regions (Supplementary Table 2).

Comparing glucose levels obtained at specialized university centers with glucose concentrations measured in other obesity clinics demonstrated no significant difference in either Germany or Sweden.

Table 3. Results of Logistic Regression Analysis for IFG adjusted for gender, age, BMI SDS and Country

\begin{tabular}{|c|c|c|c|c|}
\hline & $\begin{array}{l}\text { OR ADA } \\
\text { IFG }\end{array}$ & $(95 \%$ Cl) & $\begin{array}{c}\text { OR WHO } \\
\text { IFG }\end{array}$ & (95\% Cl) \\
\hline \multicolumn{5}{|c|}{ OR for IFG, adjusted for gender, age group and BMI SDS (Ger) } \\
\hline Age $2-<9$ y & 1.00 & ref & 1.00 & ref \\
\hline Age $9-12.9$ y & 1.67 & (1.44-1.94] & 1.71 & $(1.23-2.37)$ \\
\hline Age $13-15.9$ y & 1.59 & (1.37-1.84) & 1.72 & (1.24-2.39) \\
\hline Age $16-18$ y & 1.32 & $(1.09-1.60)$ & 1.16 & $(0.75-1.81)$ \\
\hline BMI SDS 1.8-2 & 0.64 & $(0.54-0.76]$ & 0.66 & $(0.46-0.96]$ \\
\hline BMI SDS $2-<2.5$ & 0.61 & $(0.54-0.68)$ & 0.58 & $(0.45-0.75)$ \\
\hline BMI SDS $2.5-<3.0$ & 0.73 & $(0.64-0.82)$ & 0.69 & $(0.54-0.89)$ \\
\hline BMI SDS $3.0-<4.0$ & 1.00 & ref & 1.00 & ref \\
\hline Boys vs Girls (ref) & 1.24 & (1.14-1.35) & 1.21 & $(1.00-1.45)$ \\
\hline Sweden vs Germany & 3.43 & (3.06-3.84) & 3.70 & $(2.95-4.65)$ \\
\hline \multicolumn{5}{|c|}{ OR for IFG, adjusted for gender, age group, and BMI SDS (Swe) } \\
\hline Age $2-<9$ y & 1.00 & ref & 1.00 & ref \\
\hline Age $9-12.9$ y & 1.73 & $(1.48-2.02)$ & 1.79 & $(1.27-2.51)$ \\
\hline Age $13-15.9$ y & 1.77 & (1.51-2.07) & 1.93 & (1.37-2.72) \\
\hline Age $16-18$ y & 1.50 & (1.24-1.81) & 1.33 & $(0.87-2.02)$ \\
\hline BMI SDS 2.3-2.5 & 1.00 & ref & 1.00 & ref \\
\hline BMI SDS $2.5-<3.0$ & 1.04 & $(0.94-1.14)$ & 1.04 & $(0.80-1.34)$ \\
\hline BMI SDS $3.0-<3.5$ & 1.20 & $(1.06-1.36)$ & 1.15 & $(0.85-1.54)$ \\
\hline BMI SDS $3.5-<4.0$ & 1.44 & (1.25-1.66) & 1.39 & $(1.00-1.93)$ \\
\hline BMI SDS $4.0-<4.5$ & 1.54 & (1.25-1.91) & 1.74 & (1.11-2.73) \\
\hline BMI SDS > 4.5 & 1.83 & $(1.36-2.47)$ & 1.79 & $(0.92-3.45)$ \\
\hline Boys vs Girls (ref) & 1.13 & (1.03-1.22) & 1.09 & $(0.91-1.31)$ \\
\hline Sweden vs Germany & 3.40 & (3.04-3.81) & 3.66 & $(2.92-4.60)$ \\
\hline
\end{tabular}

Abbreviations: $\mathrm{Cl}$, confidence interval; OR, odds ratio; $\mathrm{Y}$, years. $n=35633$. Results are presented using OR and $95 \% \mathrm{Cl}$. Bold numbers indicate statistically significant differences. 


\section{DISCUSSION}

This study shows that IFG is prevalent among adolescents and that there is a large difference in the prevalence of IFG among obese children and adolescents between Germany and Sweden. The total prevalence of IFG among obese children in Germany according to the ADA and $\mathrm{WHO}$ criteria was $5.7 \%$ and $1.1 \%$, respectively. In Sweden, the corresponding prevalence was $17.1 \%$ and $3.9 \%$, respectively. Although the prevalence increased with age, IFG was also relatively common among young obese children. In our cohorts, IFG was more common among boys than girls, which is consistent with some ${ }^{15,18,19}$ but not all ${ }^{20}$ previous studies.

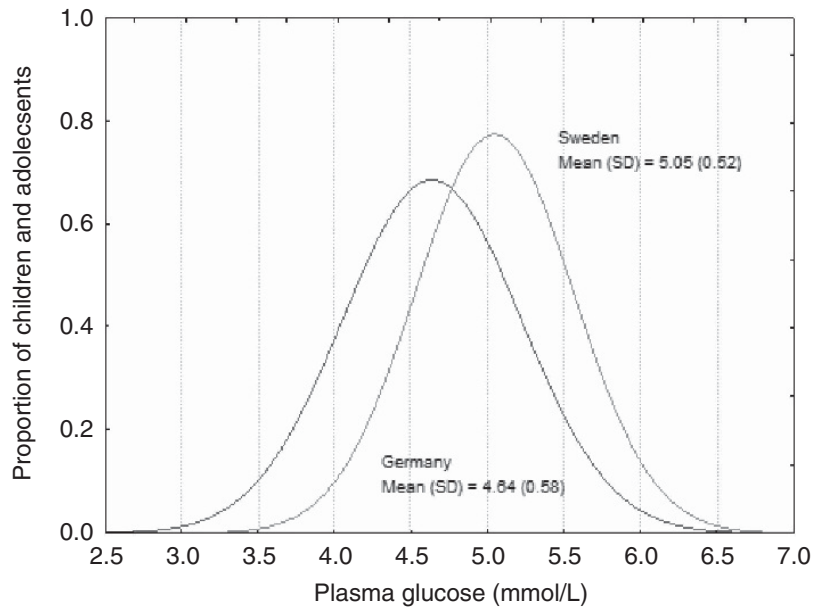

Figure 2. Distribution of fasting glucose among obese children and adolescents in Germany and Sweden.
It has previously been shown that the prevalence of IFG is higher among obese adolescents than non-obese adolescents. ${ }^{17,19}$ The present data further show that also an increased degree of obesity is associated with a higher risk for developing IFG in both children and adolescents. In addition, this study displays that the risk for IFG increases with age.

Large differences in IFG prevalence have been reported in different populations of obese adolescents. ${ }^{14,15,17-20}$ However, it is well established that IFG is an unstable condition, and hence normal fasting glucose measurements may be present between periods with IFG. ${ }^{4,27}$ Therefore, either repeated measurements of fasting glucose or large cohorts are required to establish the prevalence of IFG, and it is possible that the sample size partly can explain the previously reported differences in IFG prevalence. Another possible confounder is the methodology of the glucose measurements. As fasting plasma glucose is shown to decrease from blood sampling to the time of analysis both in serum and plasma samples, ${ }^{27,28}$ it is of importance that methodological differences of glucose measurements have been excluded.

The results in the present study are based on large and nationwide registries in Germany and in Sweden with more than 35000 glucose measurements in obese children, which is sufficient to compensate for the variability in fasting glucose measurements. Important to emphasize is that these cohorts are not population based. However, both cohorts represent urban and rural areas. The number of individuals in each cohort is about the same proportion of the whole country population, and fasting glucose measurements were available in similar frequency. Further, in both countries, independently of socioeconomic status, all children can apply for healthcare. Taken together, this indicates that the cohorts are comparable. A quality problem in the measurement of glucose is unlikely. Glucose concentrations measured in specialized university centers did not differ from concentrations measured in other centers. However,

\begin{tabular}{|c|c|c|c|c|c|c|c|c|}
\hline \multicolumn{9}{|c|}{ OR for IFG, adjusted for gender, age group and BMI SDS (Ger) } \\
\hline Age $2-<9$ y & 1.00 & ref & 1.00 & ref & 1.00 & ref & 1.00 & ref \\
\hline Age $9-12.9$ y & 2.05 & $(1.53-2.75)$ & 2.16 & $(1.10-4.23)$ & 1.57 & $(1.32-1.86)$ & 1.51 & $(1.04-2.18)$ \\
\hline BMI SDS 1.8-2 & 1.00 & ref & 1.00 & ref & 1.00 & ref & 1.00 & ref \\
\hline BMI SDS $2-<2.5$ & 0.66 & $(0.38-1.14)$ & 0.81 & $(0.21-3.10)$ & 0.99 & $(0.84-1.17)$ & 0.90 & $(0.63-1.28)$ \\
\hline BMI SDS $2.5-<3.0$ & 0.97 & $(0.58-1.64)$ & 1.05 & $(0.28-4.02)$ & 1.14 & $(0.97-1.35)$ & 1.03 & $(0.72-1.48)$ \\
\hline BMI SDS $3.0-<3.5$ & 1.27 & $(0.72-2.24)$ & 1.06 & $(0.28-4.03)$ & 1.45 & $(1.20-1.75)$ & 1.48 & $(0.98-2.24)$ \\
\hline BMI SDS $3.5-<4.0$ & 1.56 & $(0.81-3.04)$ & 1.53 & $(0.34-6.87)$ & 1.90 & $(1.46-2.48)$ & 1.67 & $(0.91-3.04)$ \\
\hline BMI SDS $>4.0$ & 3.28 & $(1.37-7.84)$ & 1.45 & $(0.20-10.48)$ & 2.00 & $(1.27-3.18)$ & 3.79 & $(1.71-8.38)$ \\
\hline Boys vs Girls (ref) & 1.24 & $(1.00-1.53)$ & 1.42 & $(0.94-2.16)$ & 1.26 & (1.14-1.38) & 1.17 & $(0.94-1.44)$ \\
\hline Age $16-18$ y & 2.25 & $(1.55-3.28)$ & 3.38 & (1.57-7.29) & 1.29 & $(1.04-1.04)$ & 0.89 & $(0.53-1.48)$ \\
\hline BMI SDS -2.5 & 1.00 & ref & 1.00 & ref & 1.00 & ref & 1.00 & ref \\
\hline BMI SDS $2.5-<3.0$ & 1.13 & $(0.54-2.35)$ & 0.95 & $(0.25-3.64)$ & 1.04 & $(0.89-1.22)$ & 1.07 & $(0.76-1.50)$ \\
\hline BMI SDS $3.0-<3.5$ & 1.40 & $(0.67-2.89)$ & 1.36 & $(0.36-5.13)$ & 1.20 & $(1.03-1.40)$ & 1.09 & $(0.77-1.55)$ \\
\hline BMI SDS $3.5-<4.0$ & 1.89 & $(0.91-3.96)$ & 1.64 & $(0.43-6.27)$ & 1.38 & $(1.16-1.65)$ & 1.31 & $(0.88-1.94)$ \\
\hline BMI SDS $4.0-<4.5$ & 1.92 & $(0.87-4.23)$ & 1.06 & $(0.25-4.55)$ & 1.51 & $(1.17-1.94)$ & 2.11 & $(1.26-3.53)$ \\
\hline BMI SDS > 4.5 & 3.17 & $(1.33-7.59)$ & 1.33 & $(0.22-7.86)$ & 1.55 & $(1.07-2.25)$ & 1.98 & $(0.92-4.26)$ \\
\hline Boys vs Girls (ref) & 1.01 & $(0.82-1.24)$ & 1.29 & $(0.85-1.94)$ & 1.15 & $(1.05-1.26)$ & 1.04 & $(0.84-1.29)$ \\
\hline
\end{tabular}


Table 5. Prevalence of IFG by gender, age and degree of obesity

\begin{tabular}{|c|c|c|c|c|}
\hline & \multicolumn{2}{|c|}{ Germany $(\mathrm{n}=32$ 907) } & \multicolumn{2}{|c|}{ Sweden $(\mathrm{n}=2726)$} \\
\hline & $\%$ IFG & $\%$ IFG & $\% I F G$ & $\%$ IFG \\
\hline & $(A D A)$ & $(W H O)$ & $(A D A)$ & (WHO) \\
\hline Girls & 5.2 & 1.0 & 16.1 & 3.3 \\
\hline Boys & 6.2 & 1.2 & 17.9 & 4.3 \\
\hline$P$-value & $<0.001$ & 0.28 & 0.22 & 0.16 \\
\hline \multicolumn{5}{|l|}{ Age (years) } \\
\hline Age $2-<9$ & 4.3 & 0.9 & 10.9 & 1.7 \\
\hline Age 9-12.9 & 6.0 & 1.2 & 18.7 & 3.4 \\
\hline Age $13-15.9$ & 6.0 & 1.1 & 18.8 & 5.4 \\
\hline Age $16-18$ & 5.3 & 0.8 & 21.5 & 5.5 \\
\hline$P$-value & $<0.001$ & 0.09 & $<0.001$ & $<0.001$ \\
\hline \multicolumn{5}{|l|}{ BMI SDS (Swe) } \\
\hline BMI SDS $<2.5$ & 5.0 & 1.0 & 11.8 & 2.6 \\
\hline BMI SDS $2.5-<3.0$ & 5.3 & 1.0 & 14.1 & 3.0 \\
\hline BMI SDS $3.0-<3.5$ & 6.0 & 1.1 & 16.8 & 4.4 \\
\hline BMI SDS $3.5-<4.0$ & 6.7 & 1.2 & 20.4 & 5.0 \\
\hline BMI SDS $4.0-<4.5$ & 6.7 & 1.7 & 18.5 & 2.9 \\
\hline BMI SDS > 4.5 & 6.1 & 1.4 & 22.2 & 2.8 \\
\hline$P$-value & $<0.001$ & 0.23 & 0.02 & 0.35 \\
\hline \multicolumn{5}{|l|}{ BMI SDS (Ger) } \\
\hline BMI SDS $<2$ & 5.3 & 1.1 & 16.9 & 3.1 \\
\hline BMI SDS $2-<2.5$ & 5.2 & 1.0 & 13.1 & 3.1 \\
\hline BMI SDS $2.5-<3.0$ & 5.8 & 1.1 & 17.5 & 4.1 \\
\hline BMI SDS $3.0-<3.5$ & 6.7 & 1.4 & 20.5 & 4.2 \\
\hline BMI SDS $3.5-<4.0$ & 8.0 & 1.4 & 23.2 & 6.0 \\
\hline BMI SDS > $>4.0$ & 7.8 & 2.7 & 36.8 & 5.3 \\
\hline$P$-value & $<0.001$ & 0.02 & $<0.001$ & 0.57 \\
\hline
\end{tabular}

cross-calibration of glucose measurements between centers within and between countries has not been carried out. Even if adjusting all measurements in Sweden according to a possible methodological decrease in the value, ${ }^{28}$ the IFG prevalence difference between Sweden and Germany remains statistically significant. In addition, the differences observed between areas within both countries are smaller than the differences between the countries, which also confirms that there is a true variation between the countries.

Our study therefore confirms that there are surprising differences in IFG prevalence between country areas. Obese Swedish children and adolescents have a 3.4- to 3.7-fold higher risk to develop the pre-diabetic stage IFG than children in Germany. The cause for this large difference between two similar European countries is unknown. Fasting glucose was normally distributed in both cohorts. This points toward systematic contributing factors to the difference in IFG prevalence between Sweden and Germany. No such factors have been identified, but they might include differences in early dietary patterns, physical activity, levels of vitamin $\mathrm{D}^{29}$ or genetics, ${ }^{30}$ as well as viral infections linked to obesity and insulin resistance. ${ }^{31}$ It has also been suggested that socio-environmental factors including the selection of food and drinks are correlated to type 2 diabetes. ${ }^{32}$ It is therefore possible that such factors also affect the risk to develop pre-diabetic stages. Interestingly, and also due to unknown reasons, the prevalence of type 1 diabetes is 2-3 times higher in Sweden as compared with Germany. ${ }^{33}$ Environmental factors rather than ethnicity seem to explain the high prevalence of type 1 diabetes in Sweden. ${ }^{34}$ Thus, it is possible that the high prevalence of IFG in Sweden is caused by environmental factors, which, in addition to obesity, ${ }^{35}$ increases the risk of type 1 diabetes in Sweden.

There are some limitations that can affect the results in this study. Only the first-taken fasting plasma glucose recording is included in this study, as we wanted to minimize the possible effect of treatment being a confounder. This might have resulted in an underestimation of IFG prevalence among the older age groups with higher prevalence of previous blood glucose measurements, which, in turn, can explain why IFG prevalence was not the highest in the oldest age group. We have not been able to adjust for parental type 2 diabetes, which might increase the risk for childhood IFG. ${ }^{36}$ In addition, there were no reliable ethnicity data from Sweden. Further, the children in the Swedish cohort were slightly more obese. As the degree of obesity was associated with fasting glucose, this could partly explain the higher prevalence. However, the IFG risks based on multivariate logistic regression analyses were adjusted for the degree of obesity.

Another issue is that all data is reported from a large number of clinical settings and not from dedicated research centers. Consequently, the accuracy in reported data might be affected as time is a critical factor in most clinical settings and, further, it is impossible to assure that all samples are obtained during fasting conditions. However, all data collection was of clinical importance, and it was in the interest of the child and the parents to obtain an accurate clinical picture.

In conclusion, we have shown that IFG is prevalent in both Germany and Sweden among obese children and adolescents, and that there are marked differences between these countries for unknown reasons. IFG in adults is strongly correlated with increased risk for future morbidity. ${ }^{9-11}$ It is plausible that IFG among obese adolescents is also a predictor for increased risk for comorbidities. $^{12}$ Our results therefore indicate that IFG is a prevalent threat of early development of obesity-related comorbidities in young obese subjects.

\section{CONFLICT OF INTEREST}

The authors declare no conflict of interest.

\section{ACKNOWLEDGEMENTS}

We specially thank all pediatric clinics that contributed to the collection and recording of data in the registers. The BORIS steering committee includes Claude Marcus, Pernilla Danielsson, Anders Ekbom, Carl-Erik Flodmark, Sven Klaesson, Jan Kowalski, Staffan Mårild and Viktoria Svensson. We are indebted to all health professionals of the APV Study Group taking care of overweight children and contributing to the APV database. This project has been supported by grants from The National Board of Health and Welfare (Sweden), the Swedish Heart-Lung Foundation and the Childhood Diabetes Foundation. Emilia Hagman has grants from the Jerring Foundation and The Swedish Order of Freemasons. The APV standardized documentation was supported by grants of the German Obesity Society (DAG) and German Federal Centre for Health Education (BzGA). The APV-study group received grant support from the German 'Competence Network Adipositas', which is initiated by the German Federal Ministry of Education and Research (grant number 01 Gl1130) and the European Foundation for the Study of Diabetes (EFSD).

\section{REFERENCES}

1 Baker JL, Olsen LW, Sorensen TIA. Childhood body-mass index and the risk of coronary heart disease in adulthood. N Engl J Med 2007; 357: 2329-2337.

2 Fontaine KR, Redden DT, Wang C, Westfall AO, Allison DB. Years of life lost due to obesity. JAMA 2003; 289: 187-193.

3 Morinder G, Larsson UE, Norgren S, Marcus C. Insulin sensitivity, VO2max and body composition in severely obese Swedish children and adolescents. Acta Paediatr 2009; 98: 132-138.

4 World Health Organization. Definition and Diagnosis of Diabetes mellitus and Intermediate Hyperglycemia: Report of a WHO/IDF Consultation, 2006.

5 Amer Diabet A. Diagnosis and Classification of Diabetes Mellitus AMERICAN DIABETES ASSOCIATION. Diabetes Care 2011; 34: S62-S69.

6 Forouhi NG, Balkau B, Borch-Johnsen K, Dekker J, Glumer C, Qiao Q et al. The threshold for diagnosing impaired fasting glucose: a position statement by the European Diabetes Epidemiology Group. Diabetologia 2006; 49: 822-827. 
7 de Vegt F, Dekker JM, Jager A, Hienkens E, Kostense PJ, Stehouwer CD et al. Relation of impaired fasting and postload glucose with incident type 2 diabetes in a Dutch population: The Hoorn Study. JAMA 2001; 285: 2109-2113.

8 Qiao Q, Lindstrom J, Valle T, Tuomilehto J. Progression to clinically diagnosed and treated diabetes from impaired glucose tolerance and impaired fasting glycaemia. Diabet Med 2003; 20: 1027-1033.

9 Levitan EB, Song Y, Ford ES, Liu S. Is nondiabetic hyperglycemia a risk factor for cardiovascular disease? A meta-analysis of prospective studies. Arch Intern Med 2004; 164: 2147-2155.

10 Jee SH, Ohrr H, Sull JW, Yun JE, Ji M, Samet JM. Fasting serum glucose level and cancer risk in Korean men and women. JAMA 2005; 293: 194-202.

11 Sorkin JD, Muller DC, Fleg JL, Andres R. The relation of fasting and 2-h postchallenge plasma glucose concentrations to mortality: data from the Baltimore Longitudinal Study of Aging with a critical review of the literature. Diabetes Care 2005; 28: 2626-2632.

12 Reinehr T, Kiess W, de Sousa G, Stoffel-Wagner B, Wunsch R. Intima media thickness in childhood obesity: relations to inflammatory marker, glucose metabolism, and blood pressure. Metabolism 2006; 55: 113-118.

13 Cali AM, Bonadonna RC, Trombetta M, Weiss R, Caprio S. Metabolic abnormalities underlying the different prediabetic phenotypes in obese adolescents. J Clin Endocrinol Metab 2008; 93: 1767-1773.

14 Valerio G, Licenziati MR, lannuzzi A, Franzese A, Siani P, Riccardi G et al. Insulin resistance and impaired glucose tolerance in obese children and adolescents from Southern Italy. Nutrition Metab Cardiovasc Disease 2006; 16: 279-284.

15 Rotteveel J, Felius A, van Weissenbruch MM. Delemarre-Van de Waal HA. Insulin resistance and the metabolic syndrome in obese children referred to an obesity center. J Pediatr Endocrinol Metab 2010; 23: 943-951.

16 van Vliet M, Gazendam RP, von Rosenstiel IA, van Zanten AP, Brandjes DP, Beijnen $\mathrm{JH}$ et al. Differential impact of impaired fasting glucose versus impaired glucose tolerance on cardiometabolic risk factors in multi-ethnic overweight/ obese children. Eur J Pediatr 2011; 170: 589-597.

17 Baranowski T, Cooper DM, Harrell J, Hirst K, Kaufman FR, Goran M et al. Presence of diabetes risk factors in a large U.S. eighth-grade cohort. Diabetes Care 2006; 29 212-217.

18 Duncan GE.. Prevalence of diabetes and impaired fasting glucose levels among US adolescents: National Health and Nutrition Examination Survey, 1999-2002. Arch Pediatr Adolesc Med 2006; 160: 523-528.

19 Williams DE, Cadwell BL, Cheng YJ, Cowie CC, Gregg EW, Geiss LS et al. Prevalence of impaired fasting glucose and its relationship with cardiovascular disease risk factors in US adolescents, 1999-2000. Pediatrics 2005; 116: 1122-1126.

20 Yamamoto-Kimura L, Posadas-Romero C, Posadas-Sanchez R, Zamora-Gonzalez J, Cardoso-Saldana G, Mendez Ramirez I. Prevalence and interrelations of cardiovascular risk factors in urban and rural Mexican adolescents. J Adolesc Health 2006; 38: 591-598.

21 Reinehr T, Wabitsch M, Andler W, Beyer P, Bottner A, Chen-Stute A et al. Medical care of obese children and adolescents. APV: a standardised multicentre documentation derived to study initial presentation and cardiovascular risk factors in patients transferred to specialised treatment institutions. Eur J Pediatr 2004; 163: 308-312.
22 Cole TJ, Bellizzi MC, Flegal KM, Dietz WH. Establishing a standard definition for child overweight and obesity worldwide: international survey. BMJ 2000; 320: 1240-1243.

23 Lobstein T, Baur L, Uauy R. Obesity in children and young people: a crisis in public health. Obesity Rev 2004; 5(Suppl 1): 4-104.

24 Karlberg J, Luo ZC, Albertsson-Wikland K. Body mass index reference values (mean and SD) for Swedish children. Acta Paediatr 2001; 90: 1427-1434.

25 Kromeyer-Hauschild K, Wabitsch M, Kunze D, Geller D, Geiss HC, Hesse V et al. Percentiles of body mass index in children and adolescents evaluated from different regional German studies. Mon schr Kinderheilkd 2001; 149: 807-818.

26 Burnett RW, D'Orazio P, Fogh-Andersen N, Kuwa K, Kulpmann WR, Larsson L et al. IFCC recommendation on reporting results for blood glucose. Clin Chim Acta 2001; 307: 205-209.

27 Santaguida PL, Balion C, Hunt D, Morrison K, Gerstein H, Raina P et al. Diagnosis, prognosis, and treatment of impaired glucose tolerance and impaired fasting glucose. Evid Rep Technol Assess (Summ) 2005; 128: 1-11.

28 Elimam A, Horal M, Bergstrom M, Marcus C. Diagnosis of hypoglycaemia: effects of blood sample handling and evaluation of a glucose photometer in the low glucose range. Acta Paediatr 1997; 86: 474-478.

29 Kelly A, Brooks LJ, Dougherty S, Carlow DC, Zemel BS. A cross-sectional study of vitamin D and insulin resistance in children. Arch Dis Child 2011; 96: 447-452.

30 Linder K, Wagner R, Hatziagelaki E, Ketterer C, Heni M, Machicao F et al. Allele summation of diabetes risk genes predicts impaired glucose tolerance in female and obese individuals. PloS ONE 2012; 7: e38224.

31 Almgren M, Atkinson R, He J, Hilding A, Hagman E, Wolk A et al. Adenovirus-36 is associated with obesity in children and adults in sweden as determined by rapid ELISA. PloS ONE 2012; 7: e41652.

32 Basu S, Yoffe P, Hills N, Lustig RH. The relationship of sugar to population-level diabetes prevalence: an econometric analysis of repeated cross-sectional data. PIOS ONE 2013; 8: e57873.

33 Adeghate E, Schattner P, Dunn E. An update on the etiology and epidemiology of diabetes mellitus. Ann N Y Acad Scie 2006; 1084: 1-29.

34 Delli AJ, Lindblad B, Carlsson A, Forsander G, Ivarsson SA, Ludvigsson J et al. Type 1 diabetes patients born to immigrants to Sweden increase their native diabetes risk and differ from Swedish patients in HLA types and islet autoantibodies. Pediatric Diabetes 2010; 11: 513-520.

35 Carlsson A, Kockum I, Lindblad B, Engleson L, Nilsson A, Forsander G et al. Low risk HLA-DQ and increased body mass index in newly diagnosed type 1 diabetes children in the Better Diabetes Diagnosis study in Sweden. Int J Obes (Lond) 2011; 36: 718-724.

36 Shahid A, Saeed S, Rana S, Mahmood S. Family history of diabetes and parental consanguinity: important risk for impaired fasting glucose in south east Asians. West Indian Med J 2012; 61: 219-223.

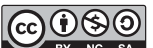

This work is licensed under a Creative Commons AttributionNonCommercial-ShareAlike 3.0 Unported License. To view a copy of this license, visit http://creativecommons.org/licenses/by-nc-sa/3.0/

Supplementary Information accompanies this paper on International Journal of Obesity website (http://www.nature.com/ijo) 